\title{
THE PROCESS APPROACH TO THE MANAGEMENT OF LOAN PORTFOLIOS
}

\author{
Pieter G Vosloo* \\ North-West University \\ Pieter.Vosloo@nwu.ac.za \\ Paul Styger\# \\ North-West University \\ Paul.Styger@nwu.ac.za
}

July 2009

\begin{abstract}
Many factors impacted the credit risk environment in the past decade, the most significant of which were the Basel II Capital Accord requirements. Foremost in the financial industry's focus was, and still is, the implementation of these requirements and their associated outcomes. In the aftermath of the Basel II implementation, credit risk managers' focus will return to understanding the portfolio philosophy in managing their credit portfolios. They will be required to adapt an integrated risk management framework, taking into account the interdependence of various building blocks, data fields and model outcomes. This paper develops and proposes a portfolio approach to the management of loan portfolios within an integrated risk management framework. The significance of this approach for the credit portfolio risk management environment and its role in maximising shareholder value are highlighted.
\end{abstract}

\section{Keywords:}

Integrated risk management framework; Enterprise-wide risk management; Credit risk management; Process approach; Credit portfolio; Corporate governance; Account life-cycle; Business Health Forum; Loan portfolios, Credit asset portfolios

\footnotetext{
* Dr Pieter G Vosloo is a senior lecturer in Risk Management and subject chair at the School of Economic Sciences at the Vaal Triangle Campus of North-West University, South Africa

\# Prof Paul Styger is the program leader in Risk Management at the School of Economics at the Potchefstroom Campus of the North-West University, South Africa
} 


\section{INTRODUCTION}

The operating environment in which banks conduct their business, especially the credit risk environment, has undergone significant changes since the latter half of the previous decade, as manifested in the Basel II proposals. This has resulted in a plethora of quantitative and qualitative credit risk information and data (Lucas, et al. 1999:2, 3), on the one hand, and, on the other, a perceived absence of a clear focus, management approach and philosophy to effectively manage credit risk. The current credit crisis exposed the deficiencies in the management of loan portfolios. In addition, current world best practice provides impetus to the viewing of risk from a holistic enterprise-wide perspective, which, together with the mentioned environmental changes, requires a formal process approach to manage loan portfolios.

Regulatory guidelines and proposals by the Basel Committee (Basel, 2003a) advocated that stricter regulatory requirements should be adopted and enforced to avoid or minimise the effects that world catastrophes (such as the Asian crisis in 1998 and the 11 September 2001 disaster) have had on the world financial systems. In terms of these regulations (Basel, 2003b), credit risk arising from large exposures and group lending will have to be covered by additional capital. In an increasingly competitive environment, the effective use of bank capital becomes a crucial issue. Quantifying credit risk results in moving away from an arbitrary risk allocation process to a scientific basis of risk-weighted capital allocation. This will inevitably result in a better utilisation of scarce capital, but also in a greater demand on management skills to manage credit effectively.

Furthermore, the activities, duties and responsibilities of company directors and executive management came under the spotlight after major international events impacted negatively on financial markets and global economies (e.g. Baring's Bank, Allied Irish Bank, Enron, Société Générale, Hadenglen Home Finance, Morgan Stanley, Fidencia and, more recently, difficulties resulting from the sub-prime debacle: AIG Insurance, Freddie Mac, Fannie Mae, Merrill Lynch, Lehman Brothers etc.). Although the drive towards greater transparency, accountability and disclosure started in 1992 with the Cadbury Code of Conduct, followed by Sarbanes-0xley, Higgs Report and, more specific for South Africa, the first and second and third reports of the King Committee on Corporate Governance in 1999, 2002 and 2009 (King I, II and III), these incidents elevated the need for directors' total oversight over all risks impacting the business being operated. A holistic view on all risks faced by financial institutions therefore becomes imperative and requires an approach where such risks can be managed prudently. Notwithstanding the objective of the Basel II Capital Accord to create a financially sound global financial system, the global economy is facing its greatest challenge ever.

The biggest challenge in managing credit risk is changing the way losses are viewed (Vosloo, 2003). A key principle is to accept that a bank can expect to lose money when it conducts business. Given this, the bank should then take cognisance and price its transactions adequately to offset expected losses with additional revenue (return) (Bessis, 2002). Banks need to consider customers' different needs, knowledge and preferences (Bessis, 2002). Inevitably, this means that various customers have different risk profiles and can therefore be charged and managed according to their level of sophistication (needs, financial prowess and acumen) (Vosloo, 2003). Since banking is about lending money to third parties, it will always be exposed to credit risk (Vosloo, 2003). The most popular way to mitigate credit risk on a transactional level is to ensure that the amount lent is secured and that the possibility of a loss is minimised (Coetzee, 2003). 
Traditionally, a loan was granted on the basis of the available security (Vosloo 2003), the client's repayment ability, and the credit risk derived from these parameters together with the knowledge of the client's business (relationship banking) (Vosloo, 2003; Milne, 2008). As the focus is directed towards soft parameters in the traditional approach (the relationship with a client provides a subjective view of the associated and perceived risk, repayment ability is monitored and security provided is a prerequisite for a loan being granted), risk per se is not quantified and deviations (defaults) are attributed to deficiencies in market and economic factors and/or client/entity parameters. For this very reason, the relationship with a client in itself mitigated the risk associated with the transaction (Serfaty, 2003). Based on the relationship with a client, financing institutions had a 'feel' for the loss they would incur in the event of default.

The management of credit risk was therefore associated with the ability to assess (know the client and the loan), to adequately provide against potential losses (based on the deterioration in a client's financial standing - pre-knowledge resulting from the relationship) and the ability to recover outstanding money. Traditionally, then, special consideration has been directed towards the loan agreement, the terms of the loan, the loan amount, the security provided, the repayment ability of the client, the standing of the client with the banking institution and, to a lesser extent, future expectation on the economic and market conditions. Incidentally, however, the traditional approach is still primarily being applied in the local industry today!

The process approach to managing credit risk in loan portfolios, reported in this paper, evolved through a strenuous research process starting with a literature study and in-depth structured interviews (guided by a questionnaire) with 12 senior executives from the six largest South African banks (Vosloo, 2003). The collective result culminated in discussion and debate at the World ERM Symposium in Chicago (Vosloo, 2005). The process approach was further amended and improved through interaction with senior executives in the banks together with input obtained from conference attendees from other international conferences (Vosloo \& Styger, 2006,2008 ). Two banks, which wish to remain anonymous, have successfully adapted and implemented this process.

This process approach requires a paradigm shift from the 'traditional' approach. The portfolio approach advocated by this paper takes the loan valuation process further by investigating the specific loan's contribution to the risk and reward profiles of the total credit portfolio. The crux of the reported investigation into the, then, current practices of credit portfolio management revealed the following deficiencies:

- Banks follow a differentiated credit management process, where some tasks are executed at branch level and others at Head Office, resulting in an unsatisfactory fragmented credit policy formulation and implementation. The absence of a holistic credit portfolio approach was cited by all the respondents as one of the main deficiencies in credit management, both locally and internationally;

- Basel II requirements resulted in a fragmented approach to credit management. The measurement for regulatory capital purposes is executed by a division of the risk management/compliance department. The evaluation of credit applications is conducted by totally remote divisions in the retail and wholesale departments, while the day-to-day account management activities resort in the branches or related Head Office department; and

- The current 'best practices' in strategic bank management still focus on interest- and 
liquidity risk (ALM/ALCO environment), market risk (Treasury/Value-at-risk environment), operations/business risk (Operational risk environment) and credit risk (Various committees, regulatory and compliance and day-to-day management departments) as independently managed processes. The failure of this methodology was highlighted by the sub-prime crisis. The application of a holistic approach by way of a Business Health Forum as described in paragraph 3.2 below would have prevented the snow-ball effect in most instances and ensured effective board oversight.

The primary objective of this paper is to describe the process approach to the management of credit risk in loan portfolios. Secondly, this paper will demonstrate that the process approach will assist executive management to ensure that the requirements (processes, systems, and data) for the effective management of credit risk in a loan portfolio are met by providing a holistic view of risk. This holistic approach rectifies the shortcomings listed above and broadens our understanding of the interdependency between profit, sustainable growth and effective credit risk management in loan portfolios. Thirdly, the process approach to credit risk management entails a new paradigm in which banks have to conduct their business in a postBasel Il environment.

This paper is organised as follows:

- Section 2 establishes the theoretical basis of the process approach to managing credit risk in a portfolio environment by investigating the different perspectives on credit risk management and discussing two distinct but dependent dimensions of credit risk management as important components in the process approach.

- Section 3 first describes the account lifecycle as the foundation of the process approach. The correct architecture of the process approach ensures that the specific data elements, systems and processes needed to implement the process approach are accounted for. Secondly, using the account cycle as a point of departure, the process approach's framework is presented.

- Section 4 provides a conclusion to the paper.

\section{THEORETICAL BASIS}

\subsection{Perspectives on credit risk management}

The two perspectives on the management of credit risk are the economic value perspective and the earnings perspective.

\subsubsection{Economic value perspective}

The economic value perspective is also known as the shareholder wealth perspective to credit portfolio risk management. The economic value perspective has an ex post focus (after default has occurred) and calculates the impact of credit risk on Credit Risk Adjusted Return on Capital (RAROC) or shareholder value (Basel, 2003b). The credit risk management philosophy and methodology therefore focus exclusively on the enhancement or maintenance of capital, because the amount not recovered in the event of default has a direct negative impact on the shareholder's wealth. 


\subsubsection{Earnings perspective}

Another perspective to credit portfolio risk management, of equal importance but not widely recognised, is the earnings perspective. The earnings perspective is duly recognised as it relates to interest rate risk (Basel 2004; Drehmann, et al. 2006) Where the economic value perspective has an ex post focus, the earnings perspective has an ex ante focus (before default occurs). The earnings perspective focuses on the loss in income for the bank as a result of and associated with the deterioration in the credit standing. It therefore has a cash flow implication to be considered. A loan's repayment generates a cash flow.

Should a client's credit standing deteriorate and he or she fail to make a payment, the nonpayment has an impact on the cash flow, resulting in a negative impact on earnings. Due to the instalment or payment not being made, the cash flow of the bank is negatively impacted. The funding requirement of the bank increases, which can cause the cost of funds of the total funding requirement to increase. The impact on the bank's liquidity and cost of funds can therefore be much greater than the mere size of the default would suggest.

The point of ultimate default is very important in this process approach and these two distinct perspectives guide the process approach before and after default.

\subsection{Credit risk management dimensions}

Two distinct but dependent dimensions, namely credit portfolio risk management and group portfolio risk management, are identified (Vosloo 2003). The first, a micro dimension, focuses on the management of the loan portfolio, while the second, a macro dimension, is directed towards the attainment of a holistic view of the total portfolio risk of the financial institution. The next section explains the micro dimension to credit risk management. The discussions that follow are based on research reported in Vosloo (2003), Vosloo (2005), Vosloo and Styger (2006) and Vosloo and Styger (2008).

\subsubsection{Credit portfolio risk management}

Credit portfolio risk management or micro portfolio risk management (because of its involvement in sub-loan portfolios and individual loans at a very detailed level) involves various sub-dimensions, namely pro-active and active credit portfolio risk management, as well as credit concentration risk management. Both the economic and earnings perspectives therefore form the basis of credit portfolio risk management.

\subsubsection{Pro-active credit portfolio risk management}

Pro-active credit portfolio risk management is concerned with the pro-active influencing of the decision-making process regarding loan approval and loan management in a portfolio context. Four key decision areas are identified where credit portfolio risk management can have a significant and pro-active influence, namely the loan marketing decision, the loan pricing decision, the loan granting decision and the credit environment.

Pro-active influencing of the loan marketing decision: Applying a credit portfolio risk management model to loan portfolios enables the credit portfolio risk manager to calculate any specific loan portfolio's contribution to overall shareholder wealth (from a credit risk perspective). As credit risk is one of the most significant risks in banking, maximising Credit RAROC should contribute significantly towards ensuring overall shareholder wealth 
maximisation. In advising the business unit whose loan portfolios or sub-portfolios are responsible for the largest contribution to earnings in its business, the credit portfolio risk manager can pro-actively influence the marketing decision. As the business units focus on the selling of those loans/credit products, diversification effects are taken into account in deriving Credit RAROC.

Pro-active influencing of the loan pricing decision: Applying a credit portfolio risk management model to loan portfolios enables the credit portfolio risk manager to calculate and compare current and target credit spreads. The credit spread assigned to a particular loan portfolio or sub-portfolio should at least be sufficient to cover the expected losses of the portfolio. Based on the inherent risk profile of the portfolio, expected losses are calculated. The pricing decision is pro-actively influenced when the credit spread is adjusted to accommodate the expected losses or anticipated expected losses, or where required, excessive spread is generated to compensate for any shortfall which might arise from other portfolios due to a competitive marketing environment. As the credit spread impacts on the Credit RAROC, the ultimate effect thereon should be analysed before a credit spread is recommended.

Pro-active influencing of the loan granting decision: The contribution that a specific loan or transaction has on the portfolio's risk profile can be quantified. The loan granting decision is therefore pro-actively influenced, as the risk contribution on a transactional level should not only enhance the risk profile on a portfolio level; the transaction should also add value towards Credit RAROC. The credit portfolio risk manager further influences the credit risk evaluation of the loan, as a recommended credit spread to be included in the pricing process is provided.

Pro-active influencing of the credit environment: Mapping the macro-economic environment to security values can for instance explain possible negative trends in recovery rates or loss rates. Using transition matrices (credit standing) can pro-actively identify negative business cycles and ensure that sufficient capacity is in place to accommodate the inflow of defaulting clients into the legal recoveries environment.

\subsubsection{Active credit portfolio risk management}

Active credit portfolio risk management entails the day-to-day application of the credit portfolio risk management approach and principles to managing loan portfolios. The day-today decision-making on all management levels (operational, tactical and strategic) is based on the principles and deliverables of the credit portfolio risk management approach being applied. It thus becomes part of the business and all its strategies. It entails what Basel II refers to as the 'user test' (Basel 2006:98). Active credit portfolio risk management enforces the use of risk mitigating strategies to create an optimum loan portfolio. Active credit portfolio risk management encompasses all the activities associated with the philosophy, approach and principles of credit portfolio risk management.

\subsubsection{Credit concentration risk management and diversification}

Applying a credit portfolio risk management model to loan portfolios enables the credit portfolio risk manager to advise management on the degree to which loan portfolios and subportfolios contribute towards concentration risk. Because unique risks create diversification opportunities within a credit portfolio context and can be diversified away, thereby enhancing Credit RAROC and shareholder value, concentration risk implies that there are no opportunities for diversification left in the portfolio. 


\subsubsection{Group portfolio risk management}

In contrast to the micro (loan-specific and sub-portfolios) focus of the credit portfolio risk management discussed above, group portfolio risk management has a macro (enterprise-wide) focus. Group portfolio risk management or macro portfolio risk management is divided into specific sub-dimensions. These sub-dimensions are Earnings at Risk (EaR), regulatory capital calculation, group capital allocation, reactive portfolio risk management, group concentration risk management and total risk diversification opportunity management. Other aspects to be overseen from a group portfolio risk management perspective are model validation (internal audit) and quality assurance in terms of systems, processes and procedures.

Applying group portfolio risk management to the total banking portfolio ensures that an independent view of risk is obtained and maintained. A natural trend (considered by the industry as best practice) is to manage the banking risks from an enterprise-wide risk framework. However, although the necessity of having a total view of all risks impacting on the financial institution is acknowledged, careful consideration should be exercised during implementation. In many instances an ineffective functional approach is adopted when applying the enterprise-wide risk management concept i.e. where the enterprise-wide established functionality tends to take on the functional activities of all the risk management activities across the financial institution. This tendency embraces ineffectiveness and even inefficiency, as the respective risks should be managed by those functions understanding the business or risk, knowing what the data relevant to that specific risk entails, and with the required intellectual capital and resources to apply in the management of a specific risk.

Group portfolio risk management and, by implication, enterprise-wide risk management should therefore adopt a process or systems approach to group risk as facilitated in a Business Health Forum (BHF). The process or systems approach sees the functional activities of every risk area as a process or a system, which from a group perspective need to be brought together to create synergetic outcomes. Even external and other internal factors and environments impact the system or process and are to be considered and made participants in the overall process.

\subsubsection{EaR, regulatory capital calculation, and group capital allocation}

EaR, an activity aiming to determine the impact risks (all the risks a banking institution is faced with) have on the earnings sustainability of the bank, can only be effectively determined from a group perspective. All the risks need to be incorporated in calculating EaR. The same group-wide view applies to the regulatory capital calculation and group capital allocation (economic capital). These activities can only be performed at group level because the regulatory capital required is determined taking into consideration each risk's regulatory requirement.

\subsubsection{Group concentration risk management and total risk diversification opportunity management}

As discussed in the previous paragraph, activities associated with capital calculation and allocation can only be performed at group level because the regulatory capital required is determined taking into consideration each risk's regulatory requirement. The implication of taking all the risks into account is that diversification opportunities might exist. Should excessive concentration be present, these risks can be transferred to the secondary market using risk mitigation strategies. 


\subsubsection{Reactive portfolio risk management}

An important role the group portfolio risk management environment plays is the establishing, maintaining and enhancing of relations with external stakeholders. Because the group portfolio risk management functionality has an independent, holistic view of the organisation and its risks, it is in a position to liaise with the regulator, analysts and other relevant parties in providing required information. It is reactive in the sense that information on current status is provided. Furthermore, because the actual management of specific risks is conducted from the functional risk environments, pro-active and active influencing of risk decisions is extremely remote. As stated, an independent view on risks needs to be maintained, and this requirement in itself does not allow for pro-active or active portfolio risk management.

The earnings and economic value perspectives as encapsulated in the micro credit portfolio and macro group portfolio credit risk management approaches culminate in the loan account lifecycle, which is the foundation of the process approach. It is described next.

\section{PROCESS APPROACH TO MANAGING CREDIT ASSET PORTFOLIOS}

\subsection{Account lifecycle}

The process approach has the loan account lifecycle, developed by Vosloo $(2003,2005)$, as its point of departure. Organising the steps in the loan portfolio risk management system according to the phases in the loan account lifecycle ensures a portfolio view of credit risk from a concentration perspective and enables the identification, assessment, management and mitigation of the inherent risks of the loan portfolio.

As specific data elements, systems and processes are needed to implement a portfolio approach in managing loan portfolios in financial institutions, a useful and easy point of departure when considering these portfolios, and the data requirements and systems required, is the account lifecycle (discussed in the following section). The loan account lifecycle framework enhances an institution's ability to monitor loan accounts during bad and good times. It also facilitates the timely identification of the deterioration in the status of loan accounts and the possible preventative mechanisms activated to minimise losses when default indeed occurs.

The loan account lifecycle as the framework for the process approach for managing loan portfolios is important as it provides:

- A logical, consecutive sequence of activities or events from which the process approach can be formulated;

- A breakdown of the key components in determining credit quality;

- A framework against which any requirements can be mapped, identified and explained;

- A framework against which concepts, dimensions and perspectives can be explained;

- A framework against which credit asset portfolios can be managed;

- A mechanism to ensure that all components of credit risk have been addressed in the process approach; and 


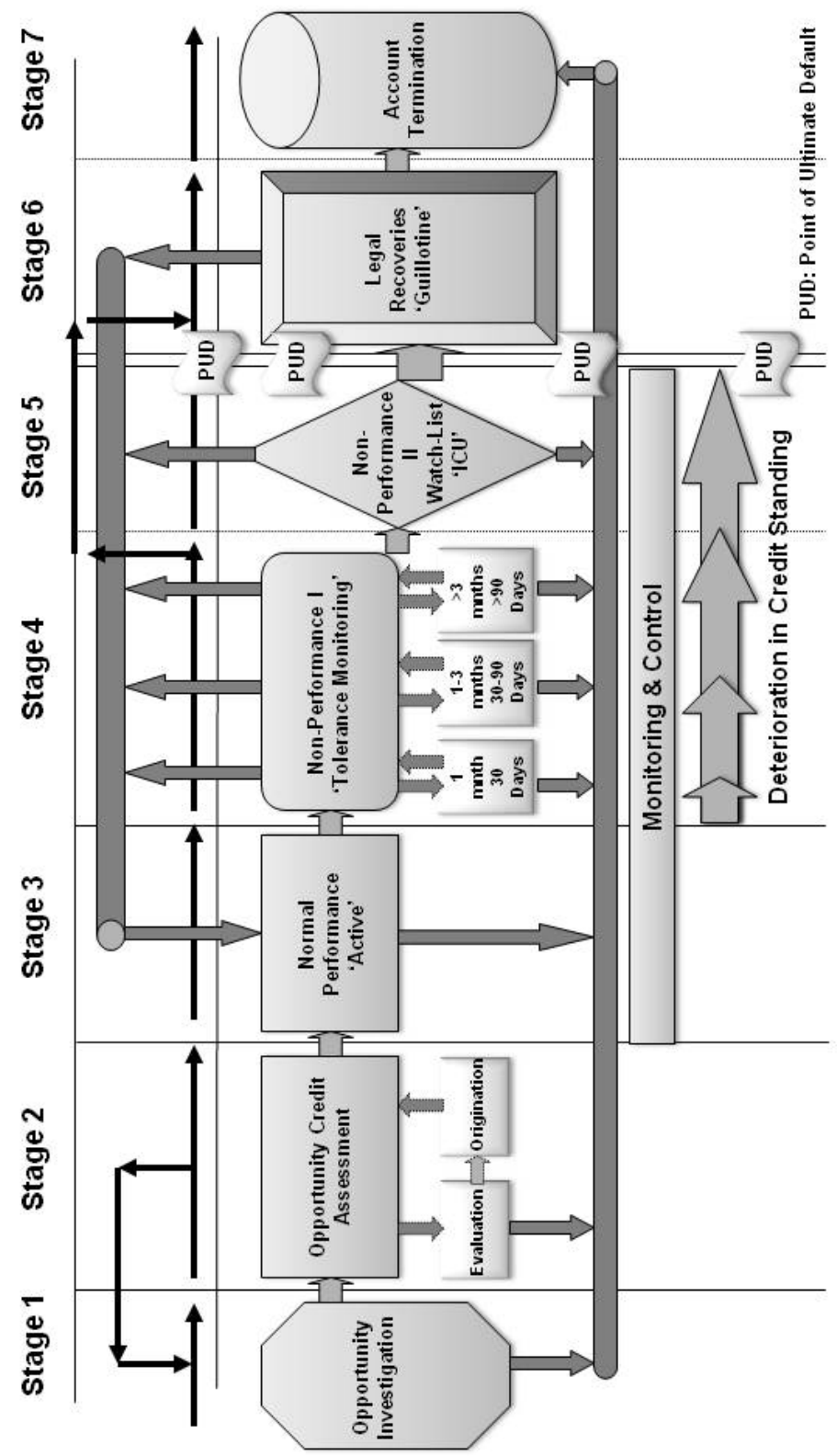

FIGURE 1: $\quad$ Loan account lifecycle framework

Source: Vosloo (2003) 
- A mechanism for the identification and origination of data variables and systems deliverables within and required by the process approach.

The loan account lifecycle consists of seven broadly defined stages, where loan accounts with different maturities are grouped together based on specific risk characteristics. FIGURE $\mathbf{1}$ depicts these stages, which are further explained in the following paragraphs.

\subsubsection{Stage 1: Opportunity identification}

During this stage clients approach the bank for a loan or are approached by sales staff of the bank. Needs are identified and a loan application is formulated for assessment by the sales staff. The outcome is closely linked to the growth targets as defined for the particular business unit of the bank. Processes in stage 1 include marketing, relationship management, sales and loan administration. During this stage a decision can be made to terminate the relationship, irrespective of whether an account has actually been opened (a 'walk-away' action).

\subsubsection{Stage 2: Opportunity credit assessment}

Two sub-stages are identified, namely: Evaluation and Origination. Once the opportunity has been identified, a formal loan application is submitted. The application's risk is evaluated in terms of transactional risk and repayment ability using both qualitative and quantitative criteria. Acceptability is determined by the overall credit risk profile of the portfolio, taking concentration risk, diversification opportunities and pricing into consideration. Should the application not meet the acceptability criteria, it is either referred back to the opportunity identification stage for reconsideration, amendment and possible resubmission, or the application is turned down, in which case the relationship or account is terminated as previously discussed. The application can either be turned down with an opportunity for resubmission, or turned down flatly, in which case the relationship or account is terminated (as part of a 'closeout' process), or the application can be withdrawn, in which case close-out happens immediately. Once approved, the loan is granted and the origination sub-stage commences. This stage acts as a formalisation of the loan whereby the facility documents are prepared and signed, the account is opened, the facilities (limits) are captured on the required systems and repayment commences on a pre-determined date. This is predominantly an administrative function. Credit risk prevails once the documentation has been signed and payment made to the client or beneficiary.

Processes involved are credit assessment, financial analyses, documentation, loan administration, and control. Systems used are inter alia credit-screening models or rating models, financial analyses, and scorecards. Also important are security types and values taken for collateralisation purposes, loan-to-value information, date of valuations if applicable, risk appetite, credit spread (pricing information) and transactional risk contribution to portfolio. The latter three elements are 'pushed' back into the system as a feedback loop derived from the credit portfolio risk management system/model.

\subsubsection{Stage 3: Normal performance}

After origination, the normal performance stage commences with the first repayment instalment being due as contractually agreed. The main characteristic of the normal performance stage is that the client continues to service his or her debt obligation (repayment of interest and capital as per agreed repayment schedule as per predetermined price). The account is monitored on a 
daily, weekly and/or monthly basis to inter alia determine if any covenants are not adhered to, the client is not experiencing financial difficulties, the account conduct is satisfactory, or whether any changes occurred to the client's profile which might impose greater risk and which the bank should be aware off. Processes involved in the normal performance stage are loan account administration, monitoring and control. Automated monitoring and control are the main activity during stage three. Credit-screening models assign a score (in the case of a behavioural scoring system a behavioural score) based on the client's conduct on the account. Account conduct forms the main driver for a number of strategies applied to the account e.g. automated limits, and out-of-order account management. During this stage a decision can be made by the client to terminate the relationship and close the account.

\subsubsection{Stage 4: Non-performance Class I (Tolerance Monitoring)}

Once a client's credit standing deteriorates i.e. the client's repayment ability is affected, default risk increases (client is moving through the various stages of delinquency). The risk of default is dependent on the credit standing of the client, which is a function of the client's ability to meet his interest and capital contractual repayment as and when due. The main driver of credit standing is the ability of the client to manage his/her cash flow irrespective of the state of the economy. As the delinquency phase deteriorates, a more vigorous loan account monitoring and control process is embarked upon. Monitoring and control processes are largely tolerance/limits driven, based on past experience, prevailing economic cycles and the prevailing business model. Interest is still accrued although the client's credit standing is deteriorating. Depending on the circumstances, management can decide to start with the raising of provisions in anticipation of an actual default - the probability of ultimate default might still be extremely low.

Because the risk of default increases as a client's credit standing deteriorates, the monitoring and control activities become more vigorous, with extensive management involvement. With an increasingly probability of default, the loan accounts are monitored on a daily, weekly and monthly basis to inter alia determine if any covenants are not adhered to. It furthermore needs to be determined if the client has met his debt obligation since the previous reporting cycle and whether any additional changes occurred to the client's profile which might impose greater risk and which the bank should be aware of. The process of monitoring and control is largely automated, and in many instances the financial institution's call centre contacts the client. The focus during this stage is on normalising the irregular accounts and accounts in arrears. However, when the efforts are not successful, certain negative outcomes can also materialise. Processes involved in the non-performance class I stage are client relationship management, loan administration, documentation, loan monitoring and control.

\subsubsection{Stage 5: Non-performance Class II (Watch-list)}

This stage is an extension of the non-performing class I stage. The reason why a distinction is made between the two stages is that circumstances may dictate that clients need to be managed out of their difficulty. The client is placed on a watch list in an 'intensive care unit (ICU)' environment. In many instances, especially when large credit exposures are involved, effort is directed at rehabilitating a client into the normal performance stage. This is done using various techniques e.g. debt rescheduling, debt restructuring, and/or management involvement. The reason for rehabilitation is to prevent or minimise losses where possible, given the market segment in which the client operates and the client's rehabilitation potential. Interest is further 
accrued, but might also be suspended depending on the circumstances as the client's credit standing deteriorates.

When a client reaches stage 5: non-performance class II, actions associated with intensive and special care have already commenced, and in all probability management has created the required provision. The process of loan monitoring and control is, in contrast to stage 4 , largely a manual process, with extensive management involvement, depending on the prevailing circumstances. Processes and systems involved are the same as in the previous stage.

\subsubsection{Stage 6: Legal recoveries}

Once all avenues to rehabilitate a client in financial distress have been exhausted, a decision is taken to transfer the client's accounts to the legal recovery environment. This action implies that the 'point of ultimate default' (PUD) has been reached. PUD differs from the Basel II definition as the Basel II Capital Accord (Basel, 2003:80) defines default as a contractual payment in arrears for at least three months. The view of this paper is that 'ultimate' default occurs at that point in the account lifecycle (PUD) where the primary focus of the bank is directed towards recovering outstanding debt. After PUD has been reached, the bank is not concerned with client relationship management and at this stage it becomes evident that the account cannot be rehabilitated back into the normal performance stage. PUD thus constitutes the point of litigation, the legal recovery process, where the client relationship is terminated and the client becomes a debtor. The aim is to recover as much as possible and to minimise the bank's losses - a 'hard' stance of debt recovery! In this regard, the importance of being able to register information at PUD becomes obvious. Not only will it identify the inflow and quantum of the legal portfolio, but it will also assist in forming an expected and unexpected loss perspective. PUD is then used in the calculation of the default rate. In the selection of PUD it is important to consider the ability for an account to be normalised because of the impact normalisation have on actual default and loss rates. Once PUD has been reached, the focus is on legal recovery.

The inability to accurately define PUD (for instance using states of delinquencies as default) would result in inaccurate credit risk spread calculations. Incorrect credit capital requirement calculations are another consequence, especially as credit-screening model calibration and credit portfolio model calibration are dependent on accurate actual data elements. It should be a requirement to disseminate the components of outstanding capital and write-offs in terms of the contributions each component makes to the overall balance - i.e. original loan capital, original security value, interest accrued, security value at PUD, provisions raised, interest suspended, legal costs, carrying costs, holding costs, amount recovered, and amount written off. The impact of these calculations on credit spreads and credit capital allocation calculations and even on a potential profit centre-underwriting model can be judged more accurately.

Security initially provided as collateral is 'encashed' and set off against any amounts due by the debtor. Where required, the bank embarks on a process of litigation against the former client. Monitoring still takes place, but from a reporting perspective on the recovery progress rather than a client status perspective. Interest is suspended or terminated (stopped) depending on the circumstances, and the provision is evaluated against the expectation of recovery given the economic cycle, the market conditions and costs associated with the envisaged legal process. 


\subsubsection{Stage 7: Account termination}

The account termination stage is mainly a 'close-out' stage for the account, indicating that the end of the account lifecycle has been reached. It is more a theoretical concept for illustration and discussion purposes.

Section 3.1 described the loan account lifecycle and its seven stages used as the foundation of the process approach. Establishing the correct architecture of the process approach ensures that the specific data elements, systems and processes needed to implement the process approach are accounted for. In Section 3.2 the approach's framework is presented.

\subsection{Process approach to managing credit asset portfolios}

The account lifecycle as a departure point (discussed above) provides the fundamental building block on which the process approach framework (depicted in FIGURE 2A and FIGURE 2B) can be formulated. From a credit risk perspective, the account lifecycle, shown as 'A' in FIGURE 2A, provides insight into the various stages of an account to which existing policies, processes, systems and data deliverables can be mapped and evaluated. Each of these stages is accompanied with procedures, processes and policies by which a particular stage's credit risk management should be executed.

In addition, specific systems and data deliverables, shown as 'B' in FIGURE 2A, form part of the information architecture. The latter is aligned to the stage processes, policies and procedures mentioned previously, the segmented business environment as depicted by the financial institution's specific business model, and to supporting systems providing non-credit risk related data deliverables to be used in credit portfolio risk management. Gap analysis at both the account level and system interface level provides information on the adequacy of previously mentioned processes, systems and data against pre-determined parameters originated from and specified in the dimensions to credit risk management.

Shortcomings with respect to segmentation analysis, system and data requirements, and system configuration are highlighted to allow for steps to be taken in closing these gaps. As data deliverables are provided by different systems (e.g. financial, product, business and segment, vendor specific, market etc.), in many instances using different programming languages, all data deliverables are to be exported into a systems interface, where data deliverables are converted using a singular programming language from which a single 'view of the truth' can be obtained. Data definitions are to be aligned and documented in order to assist in obtaining a single 'view of the truth'.

The credit portfolio risk management system, shown as ' $C$ ' in FIGURE 2A, sources its data requirements from the systems interface module to enable the application of credit portfolio risk management. The analysis of data, through statistical inference, provides specific deliverables such as default probabilities, default exposures, potential loss should default occur etc., which are applied and modelled to enable pro-active and active credit portfolio risk management. The key outcomes of the modelled deliverables together with other data variables, the institution's risk appetite and risk tolerance levels, allow the credit environment's contribution to shareholder wealth to be determined. The credit portfolio risk management system allows credit to be managed by those who understand the business or credit risk environment, knowing what the data relevant to that specific risk entails, and with the required intellectual capital and resources to apply to the management of credit risk. 


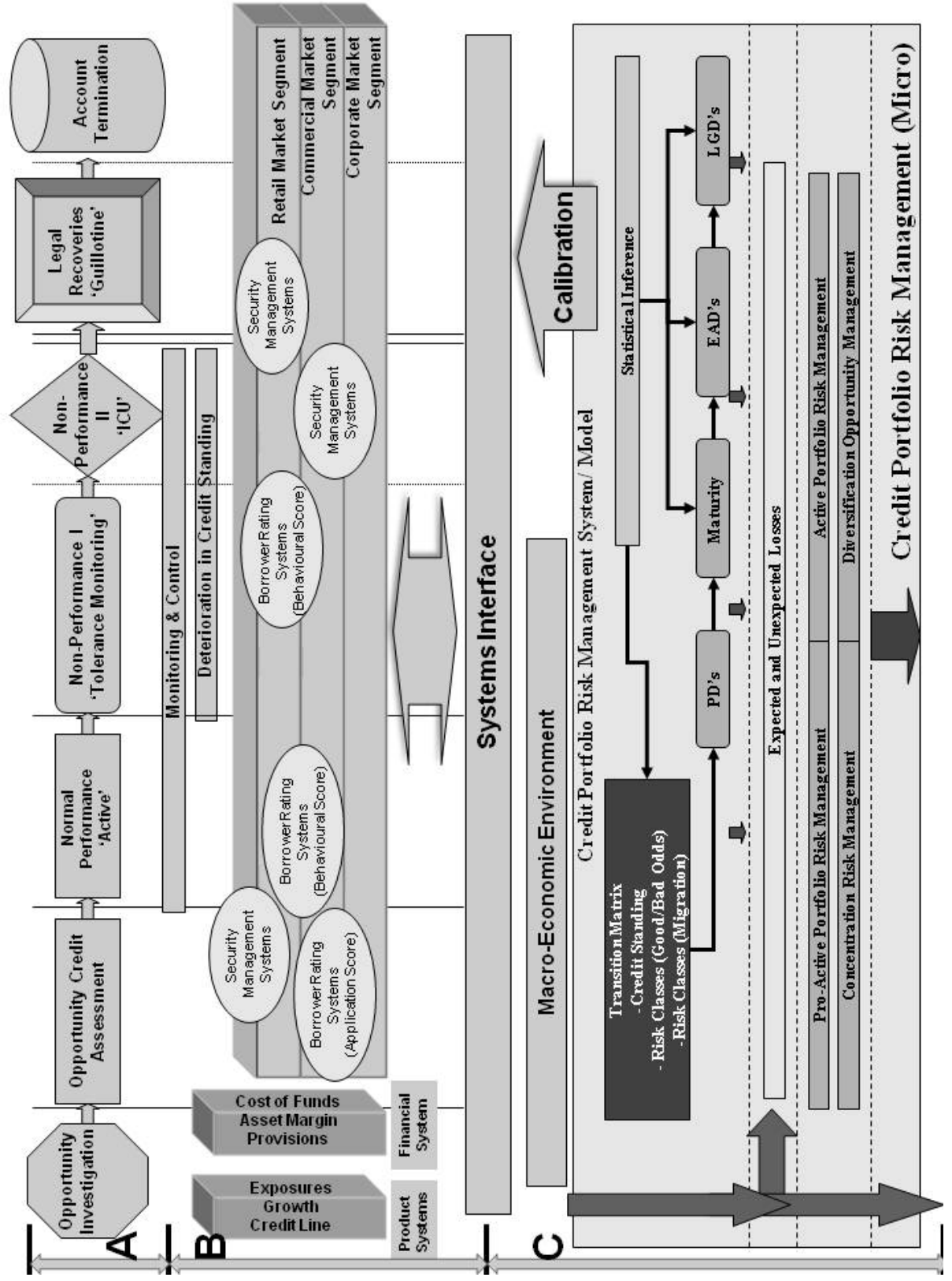

FIGURE 2A: Framework depicting the Process Approach to Managing Credit Asset Portfolios Source: Author

Through a model interface, the deliverables associated with the credit portfolio risk management system as well as deliverables associated with other risk areas are provided and applied to group portfolio risk management, shown as 'D' in FIGURE 2B. A total banking portfolio 
view is thus provided, ensuring that an independent view of all major risks is obtained, maintained, assessed and acted upon. Obtaining a total banking portfolio view assists in Earnings at Risk calculations, regulatory and economic capital calculations and capital allocation to different strategic business units and risk environments. Overall risk concentration management is also facilitated.

Banking risks are managed within an enterprise-wide risk management framework and should therefore adopt a process or systems approach to group risk as facilitated in a Business Health Forum (BHF), shown as ' $\boldsymbol{\varepsilon}$ ' in FIGURE 2B. The process or systems approach views the functional activities of every risk area as a process or a system, which, from a group perspective, need to be brought together to create synergetic outcomes. Even external and other internal factors and environments impact on the system or process and are to be considered in the overall process.

Adopting a Business Health Forum 'framework' means that an independent view of all the risks and activities is ensured. Internal and external risk factors are considered and scenario analyses applied taking into account the strategic objectives of the institution, its risk appetite, risk tolerance levels, various business unit business plans and marketing targets, legislation and overall economic environment. Strategies are developed and simulated after which the most appropriate strategy is selected, and tabled at the board committee for approval. Once approved, targets are established, communicated, monitored, evaluated, reviewed and, if necessary, amended while still being aligned to the approved strategy. The forum ensures an independent view of all the risks and activities of the business, including credit risk, by the board of directors.

The data definitions are to be aligned and documented in order to assist in obtaining a single 'view of the truth'. The Business Health Forum also facilitates the role of the credit portfolio risk manager as 'executioner' and 'advisor' of the overall business credit strategy, as the credit portfolio risk management functionality is represented at the Business Health Forum. On the one hand credit portfolio risk analyses, credit risk appetite, credit concentration, and diversification can be shared with the forum to be included in the 'what if' scenarios and strategies, while, on the other hand, pertinent information can be acquired from other representative, e.g. target markets, growth targets, and pricing.

Because the most appropriate strategy is recommended, and results and strategy effectiveness communicated to the board committee(s), which in turn reports to the board of directors, the process approach facilitates risk management oversight at board level. Each environment, process or system potentially impacting the overall business strategy is involved in the Business Health Forum thereby ensuring a holistic and unified view on all risks impacting the bank. In addition, alignment between all relevant plans, business unit strategies and processes is enhanced. 


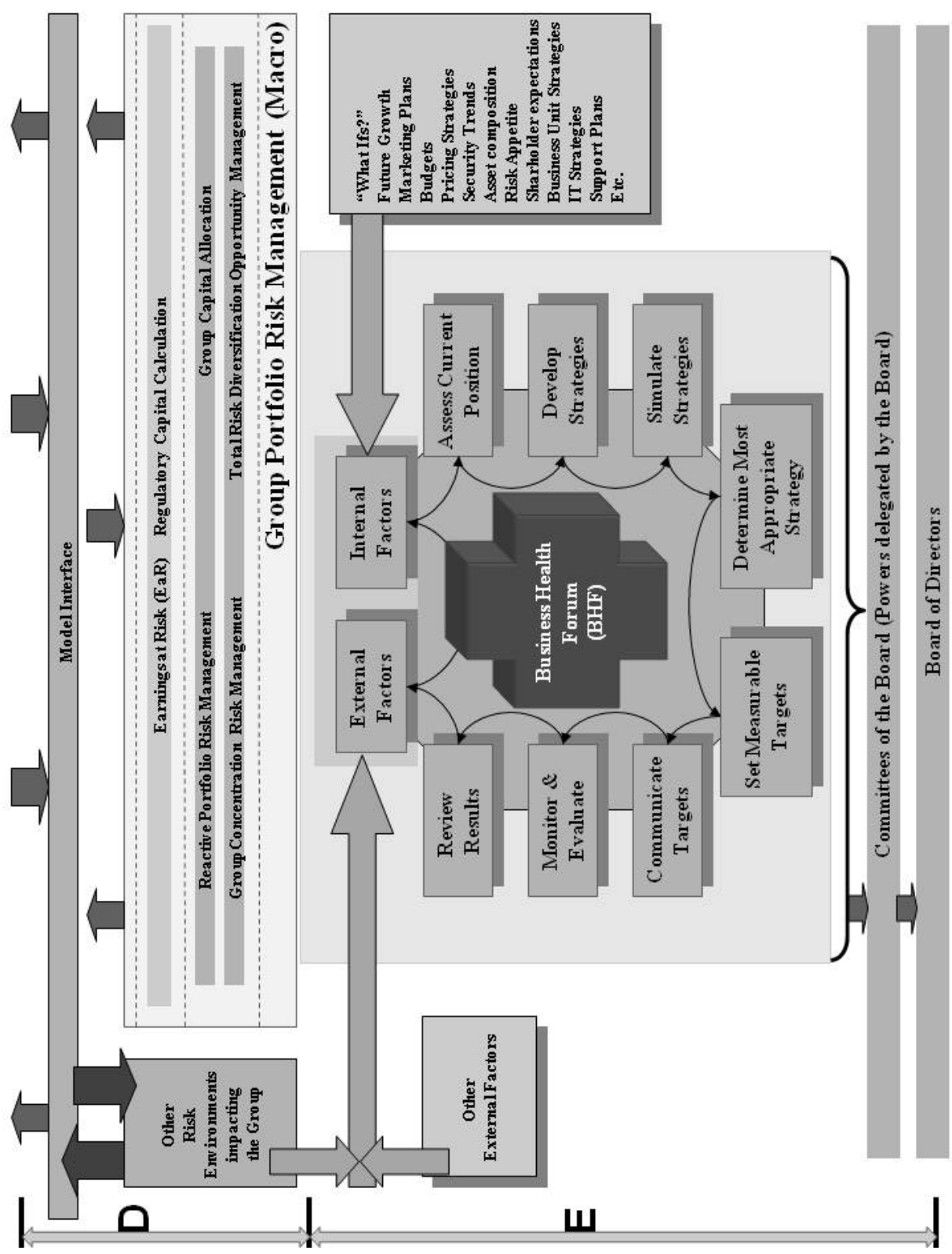

FIGURE 2B: Framework depicting the Process Approach to Managing Credit Asset Portfolios Source: Author 


\section{CONCLUSION}

A portfolio risk management approach forces a paradigm shift from the traditional way credit risk was understood, enforced and managed towards a new credit culture, a new management ethos and approach to establish business drivers, in which credit risk is assessed by utilising information derived from various systems and credit risk processes. This necessitates a transition from the 'old' to the 'new', thereby embracing best-of-breed methodologies in the management of credit risk. An approach based on the account lifecycle, supported by the necessary information systems and driven by the Business Health Forum, is the solution.

The application of the portfolio approach to managing loan portfolios allows for pro-active portfolio risk management to be applied. The portfolio approach allows for pro-active influencing of the marketing decision, the credit decision and the pricing decision in order to maximise shareholder wealth. Furthermore, the approach allows the user to determine on a dayto-day basis (real time) the extent of mitigation that is required to address specific objectives, and to utilise resources in those areas where they are most required. Applying the portfolio approach requires that a formal approach be followed to ensure that the required data elements, systems and processes needed for the portfolio approach are identified and available, so that business objectives can be met.

Adopting and applying the developed framework will assist executive management to ensure that the requirements (processes, systems, and data) for effective credit portfolio risk management are met. It would also broaden the understanding regarding the interdependency between profit, sustainable growth and effective credit portfolio risk management. Lastly, it will assist directors of financial institutions to exercise their fiduciary and judiciary duties, roles and responsibilities.

\section{REFERENCES}

Basel Committee on Banking Supervision. 2003a. Overview of the New Basel Capital Accord: Issued for comment by 31 July 2003. 3rd Consultative Document. April 2003. Bank for International Settlements.

Basel Committee on Banking Supervision. 2003b. The New Basel Capital Accord: Issued for comment by 31 July 2003. 3rd Consultative Document. April 2003. Bank for International Settlements.

Basel committee on banking supervision. (2004). Principles for the Management and Supervision of Interest Rate Risk. July 2004. Bank for International Settlements.

Basel committee on banking supervision. (2006). International Convergence of Capital Measurement and Capital Standards: A Revised Framework Comprehensive Version. June 2006. Bank for International Settlements.

Bessis, J. (1999). Risk Management in banking, $1^{\text {st }}$ edition. Chichester: Wiley.

Bessis, J. (2002). Risk Management in banking, $2^{\text {nd }}$ edition. Chichester: Wiley.

Coetzee, J. (2 September 2003). General Manager: CRMO Risk Management Services, Absa Bank. Verbal communication with the author held on 2 September 2003. Johannesburg. (Audiotape not in possession of author - informal discussion)

Drehmann, M., Sorensen, S. \& Stringa, M. (2006). Integrating credit and interest rate risk: A 
theoretical framework and an application to banks' balance sheets. June 2006. London: Bank of England.

Lucas, A., Klaassen, P., Spreij, P. \& Straetmans, S. (1999). An Analytic Approach to Credit Risk of Large Corporate Bond and Loan Portfolios. February 1999. Faculteit der Economische Wetenschappen en Econometrie. Serie Research Memoranda 1999-1 8. Amsterdam: Vrije Universiteit.

Milne, F. (2008). Credit Crises, Risk Management Systems and Liquidity Modelling. (John Deutsch Institute for the study of economic policy. Working papers on Economic Policy No. 1, 9-2008.)

Ontario: John Deutsch Institute - Queen's University Canada.

Serfaty, P.S. (2003). The Changing Nature of Credit Relationships and Banking. (In Frontiers in Credit Risk: Concepts and techniques for applied credit risk measurement.) Singapore: Wiley.

Vosloo, P.G. (2003). A Process Approach for Managing Credit Asset Portfolios in a South African Bank. Unpublished PhD thesis. Potchefstroom: Potchefstroomse Universiteit vir Christelike Hoër Onderwys.

Vosloo, P.G. (2005). Process Approach for Managing Credit Asset Portfolios. Presentation at $3^{\text {rd }}$ Enterprise-wide Risk Management Symposium of the Professional Risk Managers' International Association and the Society of Actuaries: Chicago, USA. May 2005.

Vosloo, P.G. \& Styger, P. (2006). Process Approach to Credit Risk Management as applied to Crops and Harvests. $61^{\text {st }}$ Annual Conference of the International Economic Society, Berlin, March 2006. Germany.

Vosloo, P.G. \& Styger, P. (2008). Risk Rating of non-listed Co-operative Banks. $5^{\text {th }}$ Applied Financial Economics Conference, Samos, July 2008. Greece. 